\title{
Article \\ The Association of Self-Esteem with the Level of Independent Functioning and the Primary Demographic Factors in Persons over 60 Years of Age
}

\author{
Dorota Ryszewska-Łabędzka ${ }^{1}$, Sławomir Tobis ${ }^{2}$ D , Sylwia Kropińska ${ }^{3}$, Katarzyna Wieczorowska-Tobis ${ }^{3, *}$ \\ and Dorota Talarska $4, *$ (D) \\ 1 Department of Nursing, Stanislaw Staszic State University of Applied Sciences, 64-920 Pila, Poland; \\ d.labedzka69@gmail.com \\ 2 Department of Occupational Therapy, Poznan University of Medical Sciences, 60-781 Poznan, Poland; \\ stobis@ump.edu.pl \\ 3 Geriatric Unit, Department of Palliative Medicine, Poznan University of Medical Sciences, \\ 61-245 Poznan, Poland; skropins@ump.edu.pl \\ 4 Department of Preventive Medicine, Poznan University of Medical Sciences, 60-781 Poznan, Poland \\ * Correspondence: kwt@tobis.pl (K.W.-T.); dtalarska@ump.edu.pl (D.T.)
}

check for updates

Citation: Ryszewska-Łabędzka, D.; Tobis, S.; Kropińska, S.;

Wieczorowska-Tobis, K.; Talarska, D. The Association of Self-Esteem with the Level of Independent

Functioning and the Primary Demographic Factors in Persons over 60 Years of Age. Int. J. Environ. Res. Public Health 2022, 19, 1996. https:// doi.org/10.3390/ijerph19041996

Academic Editors: Carmen de Labra Pinedo, Marta Elena Losa-Iglesias, Daniel López-López and Ricardo Becerro de Bengoa Vallejo

Received: 27 December 2021

Accepted: 7 February 2022

Published: 10 February 2022

Publisher's Note: MDPI stays neutral with regard to jurisdictional claims in published maps and institutional affiliations.

Copyright: (C) 2022 by the authors. Licensee MDPI, Basel, Switzerland. This article is an open access article distributed under the terms and conditions of the Creative Commons Attribution (CC BY) license (https:// creativecommons.org/licenses/by/ $4.0 /)$.

\begin{abstract}
Self-esteem reflects the way we see ourselves. The aim of this study was to determine the relationship among self-esteem, bio-psycho-social functioning, and sociodemographic conditions in the elderly. The study included 300 individuals over 60 years of age living in their home environment. The employed research tools included the Abbreviated Mental Test Score, Rosenberg Self-Esteem Scale (RSES), and EASYCare Standard 2010 questionnaire involving the following scales: independence score, risk of breakdown in care, and risk of falls. Results: The average score achieved by the study group according to the RSES scale was $29.9 \pm 5.6$ points. In addition, the study group presented a low risk of independence loss (independence score $13.3 \pm 18.1$ ), risk of breakdown in care $(4.4 \pm 2.4)$, and risk of falls $(1.8 \pm 1.6)$. The conducted multivariate analysis demonstrated that a significant $(p<0.05)$ negative predictor of low self-esteem was education below the secondary level, a poor financial condition, and functional limitations in domain I (seeing, hearing, and communicating skills) of the EASYCare Standard 2010 questionnaire. A relationship was found between self-esteem and the level of bio-psycho-social functioning, as well as between education and the financial situation. The results demonstrate that even successfully ageing individuals require a regular assessment of their functional status and individually adapted support in order to maintain independence and to increase their self-esteem.
\end{abstract}

Keywords: self-esteem; the elderly; functional state; care needs

\section{Introduction}

Self-esteem is defined as the subjective assessment of one's own worth. It includes the feeling of self-acceptance and a positive attitude towards oneself [1-3]. In fact, the general feeling of self-esteem is referred to as global and is contrasted with specific self-esteem, which relates to the assessment of a person's involvement in various areas of life, such as in social or professional roles. Global self-esteem constitutes a unidimensional concept affecting specific self-esteem [4]. Self-esteem can be analysed both in terms of a trait and a state. As a trait it is characterised by a stable evaluation of oneself, whereas as a state it is based on a specific context, and thus can change due to situational factors [5].

A person develops a sense of self-esteem as a result of positive and negative experiences in life. The greatest increase in self-esteem occurs during childhood and adulthood, and it reaches its peak at approximately 60-70 years of age, and gradually declines with age $[1,6]$. This may stem from poorer physical and mental functioning, deterioration in social status, financial situation, and the loss of loved ones [7]. 
In contrast, the elderly tend to accept their functional limitations, which may be reflected in a more positive perception of oneself [6]. A similar effect is frequently observed in individuals who reject stereotypes regarding old age and view themselves more positively. These individuals tend to accept changes in appearance and functional limitations and are willing to undertake new life challenges and participate in social life [8,9]. Is it worth noting that the elderly who are self-confident present higher self-esteem and are more capable of coping with psychosocial issues. On the other hand, individuals who are dissatisfied with their lives or have negative past experiences are less confident, and they view themselves less favourably [10]. Additionally, self-esteem is a significant element in the adaptation processes, and it does not depend on age but on one's level of social integration and ability to manage challenging life situations [7,11,12].

Positive self-esteem also provides the basis for the development and maintenance of mental health $[9,13]$. Moreover, it is a vital element in health promotion, as it is conducive to well-being and a sense of happiness $[8,10,12]$. It also influences better functioning in emotionally difficult situations, such as illness or isolation during a pandemic. A low self-esteem, on the other hand, results in withdrawal from new activities. Additionally, it can be a risk factor for the development of depression, anxiety, and eating disorders as well as for the formation of inappropriate defence mechanisms, such as acts of violence, addiction to alcohol, or psychoactive drugs [12-15].

Many factors determine the development of self-esteem, and those most commonly identified include a reduced physical capacity and mental ability, increase in symptoms due to comorbidities, gender, ethnicity, socioeconomic status, social relationships, stressful life events, retirement, and the need for gait stabilisation equipment, as well as the loss of a spouse and incidents of previous falls [1,7,10,12,16-21]. Other significant elements include respect and attention from loved ones, including family members, and a sense of meaning in life $[16,22,23]$.

The elderly's perception of themselves and the ageing process affects their assessment of the quality of life $[8,9,20,24]$. Furthermore, both the assessment of self-esteem and the quality of life depends on the level of the independent fulfilment of needs [8,9,25-27]. Another common problem of the elderly is disability. In old age, apart from the changes associated with the aging process itself, the exacerbation of symptoms of chronic diseases is observed. Consequently, the number of persons requiring support increases as well [28,29], although an increasing number of elderly individuals are active and classified as part of the successful ageing group. Therefore, the organisation of care for the elderly that represents a major logistical and financial challenge for both the state and the family. The variety of problems in groups of senior citizens, as well as their varying expectations, indicate the necessity of a multifaceted approach when planning support, i.e., the cooperation of the healthcare system, social care, regional programmes, and cooperation with the elderly and their carers. Hence, since independence is one of the factors promoting high self-esteem, the support provided should promote actions to improve and create environments conducive to maintaining the independence of the elderly. Such measures will contribute to reducing health care costs and to improving the quality of life of the elderly $[10,20]$.

It is vital to bear in mind that functional limitations in the elderly usually develop gradually. Therefore, periodic monitoring of their health status and functional ability allows for the appropriate support, and thus maintains the independence of this group until they reach an older age. One of the tools recommended for monitoring functional ability is the EASYCare Standard 2010 questionnaire [30,31]. It facilitates the assessment of various activities, which definitely constitutes an advantage of this tool, since the level of human functioning is important not only biologically, but also psychosocially. Most studies conducted in the elderly indicate the impact of physical and mental health, social relations, physical activity, or place of residence (community, nursing home) on self-esteem. However, little research has been conducted investigating the relationship between the level of self-satisfaction of biological, psychological, and social needs and self-esteem. Therefore, 
the aim of our study was to determine the associations among self-esteem, the level of the bio-psycho-social functioning, and the sociodemographic conditions in the elderly.

\section{Materials and Methods}

\subsection{Organization of the Study}

The cross-sectional study was conducted between October and November 2019. The research location was a family doctor's outpatient clinic (GP), where a family doctor and a community nurse provided free medical care as part of state-funded health insurance. Participation in the study was offered to anyone who received medical advice during the study period and was at least 60 years old. During registration, patients were informed about the conducted study, and they were asked whether they agreed to participate. The questionnaire was filled in by the subjects following an appointment with a GP, in a separate room, in the presence of a nurse. The participants mostly completed the questionnaire on their own. Nurses assisted 10 subjects, who had forgotten their glasses, with reading and completing the questionnaire. The participation in the study was voluntary, and the study initially included 316 participants. Subjects who provided verbal consent were asked to complete the part of the questionnaire containing questions referring to the inclusion and exclusion criteria.

The inclusion criteria were as follows: 1 . age $\geq 60$ years; 2 . residence in a house or a block of flats; and 3. the ability to communicate. The exclusion criteria were as follows: 1. cognitive impairment, on the basis of the AMTS (Abbreviated Mental Test Score) scale. Individuals who scored 7 points or more, which indicated they were cognitively fit, were qualified for further study; and 2. a disease process or disability which prevents independent functioning. The study group scored $9.9 \pm 0.5$ points (median: 10; range 7-10 points) on the AMTS scale.

Finally, 300 individuals were included in the study and completed research questionnaires labelled with an identification number. Fourteen persons were excluded from the study, as they did not meet the inclusion criteria, and 2 persons opted out on their own in the course of completing the questionnaires.

Prior to the distribution of the questionnaires, the nurses reminded the subjects once again of the voluntary character of their participation in the study. Additionally, a declaration was provided on the first page of the questionnaires, in which the patient stated that participation in the study was voluntary and that they had read the questionnaires.

\subsection{Research Tools}

1. AMTS scale (Abbreviated Mental Test Score, Hodkinson, 1972) [32]—used for the screening assessment of cognitive function. The scale ranges from 0 to 10 points. The score indicating normal mental performance is between 7 and 10 points. This tool was employed only when verifying the group, in order to evaluate the inclusion criterion.

2. Rosenberg Self-Esteem Scale (RSES).

The RSES scale according to the Polish edition by Łaguna et al. was applied [18]. The validated questionnaire for the Polish population demonstrated good psychometric properties (reliability and validity). It consists of 10 statements to which the participant responds by choosing 1 of 4 possible statements, according to the Likert scale ranging from: 1 -strongly agree to 4-strongly disagree. Thus, the range of scores for the entire scale is from 10 to 40 points. In the Polish version of the score, the scores for items 1, 2, 4, 6, and 7 should be reversed. The general assessment principle assumes that the higher the final score, the higher the feeling of self-esteem.

Authors of the previous papers interpreted the results of the RSES scale differently $[2,3,10,12,14,24]$. In our study, we used the following scoring: low self-esteem was indicated by $10-27$ points and high self-esteem by $28-40$ points, taking into account the median (28 points) and $60 \%$ of the obtained score on the axis of $10-40$ points.

3. EASYCare Standard questionnaire 2010. 
The EASYCare Standard questionnaire 2010 was implemented to assess independent functioning. The tool is recommended for the elderly when assessing care needs (need for support) [30,31]. The Polish version of the tool was adapted by Bien et al. [33]. The uestionnaire consists of two parts. Firstly, information regarding the patient and his family situation is collected, and secondly, the level of independent functioning is assessed in 7 domains: I: seeing, hearing and communicating (4 items); II: looking after yourself (13 items); III: getting around (8 items); IV: your safety (5 items); V: your accommodation and finance (3 items); VI: staying healthy (7 items); and VII: your mental health and well-being (9 items).

On the basis of the collected information, a list of the identified caring needs is established, reflecting the activities in which a person is not independent. In these domains the elderly require support, and hence they become priorities when organizing care.

The last summarizing element are the following three scales providing information from the previously analysed domains:

- Independence score-indicates the independence of a person in terms of dressing, caring for appearance, bathing, preparing meals, moving around independently, and managing finances. The number of points that can be received is $0-100$ points. The higher the number of points received, the greater the risk of dependence.

- Risk of breakdown in care-reflects the risk of hospitalization on the basis of the obtained answers concerning such activities as dressing, bathing, using the toilet, and assessing health and well-being, as well as memory loss, depression and/or pain. Scoring range is $0-12$ points. With an increase in the number of points, the risk of $24 \mathrm{~h}$ care increases.

- Risk of falls - is evaluated on the basis of the analysis of the difficulties in movement, foot problems, and feeling of safety at home and outside, as well as the number of falls in the last 12 months. Scoring range is $0-8$ points. Scoring 3 or more points indicates a high risk of falls.

\subsection{Statistical Analysis}

The comparison of independence score, risk of brake down, and risk of falls between two groups of patients (60-69 years vs. 70 and above) was performed by the Mann-Whitney test since data did not follow the normal distribution (Shapiro-Wilk test). The categorical data, including age, marital status, place of residence, education, form of residence, requiring a carer, and low or high self-esteem, were compared using the $\mathrm{chi}^{2}$ test for independence. Spearman's rank correlation coefficient was used to analyse the relationship between the results of the EASYCare questionnaire and the RSES scale.

In addition, a univariate and multivariate logistic regression analysis was conducted to determine the effects of demographic and social variables on the functioning of the elderly in each of the EASYCare Standard 2010 domains and the risk scales, as well as on the level of self-esteem (RSES). For the multivariable logistic regression, a stepwise backward selection procedure was used. All the tests were considered significant at $p<0.05$.

Statistical calculations were performed using TIBCO Software Inc. (2017; Palo Alto, CA, USA), Statistica version 13.

\section{Results}

\subsection{Characteristics of the Studied Group}

The study involved a group of 300 individuals (see Table 1), where almost 2/3 were women $(64.7 \%)$. The average age was $70.5 \pm 7.5$. The majority $(54.7 \%)$ of the subjects in the group were aged 60-69 years. Additionally, the majority $(80.0 \%)$ lived in the city and had completed secondary education (40.7\%). The married couples accounted for $59.3 \%$ of the group. A total of $52.6 \%$ of the women and only $18.9 \%$ of the men had no life partner. A total of $26.7 \%$ of the subjects lived alone. A total of $15.7 \%$ of participants provided care for another person, which concerned women more often. Only about $\frac{1}{4}(24.0 \%)$ of the group benefited from the care of other persons. The majority $(61.7 \%)$ reported they were in good financial condition. 
Table 1. Characteristics of the studied group—demographic variables.

\begin{tabular}{ccc}
\hline Variable & Classification & Total \\
& & $\mathbf{N}(\mathbf{\%})$ \\
\hline \multirow{3}{*}{ Gender } & Entire group & $300(100.0)$ \\
& Women & $194(64.7)$ \\
Age & Men & $106(35.3)$ \\
& Entire group & $70.5 \pm 7.5$ \\
Place of residence & 60-69 years of age & $164(54.7)$ \\
& Over 70 years of age & $136(45.3)$ \\
& Rural areas & $60(20.0)$ \\
Marital status & City & $240(80.0)$ \\
& Single & $21(7.0)$ \\
& Married & $178(59.3)$ \\
& Divorced & $9(3.0)$ \\
Education & Widow/Widower & $92(30.7)$ \\
& Elementary & $54(18.0)$ \\
& Vocational & $86(28.7)$ \\
& Secondary & $122(40.7)$ \\
& Higher & $38(12.7)$ \\
& Single & $80(26.7)$ \\
& As a couple & $115(38.3)$ \\
& In a family & $105(35.0)$ \\
\hline
\end{tabular}

\subsection{Self-Esteem in the Studied Group}

On the Rosenberg Self-Esteem Scale (RSES), the study group scored $29.9 \pm 5.6$ points, which indicates an average self-esteem according to the adopted distribution. A low self-esteem was found in $23.3 \%$ of the group.

Following the analysis of the demographic and social variables, significant differences in low self-esteem were demonstrated only with such predictors as education with $6.3 \%$ having a secondary and higher education level vs. $17.0 \%$ having an education below the secondary level $(p<0.001)$, place of residence with $6.0 \%$ living in urban areas vs. $17.3 \%$ living in rural areas $(p<0.025)$, financial condition with $15.7 \%$ having a good financial condition vs. $35.7 \%$ with a poor financial condition $(p<0.007)$, and requiring a carer with $43.0 \%$ requiring a carer vs. $17.1 \%$ not requiring a carer $(p<0.001)$. Individuals whose education was below the secondary level, living in the rural areas, having a poor financial condition, and requiring the support of a carer presented lower self-esteem. The analysis of individual questions from the RSES scale with demographic and social variables revealed a difference in self-esteem assessment in all questions regarding education and requiring a carer.

\subsection{Functional Level of the Studied Group-EASYCare Standard 2010 Questionnaire}

Out of the seven domains of the EASYCare Standard 2010 questionnaire, the majority of subjects reported limitations in independent functioning in domain VI-staying healthy and VII-your mental health and well-being, whereas the least number of subjects reported limitations in domain I-seeing, hearing, and communicating (see Figure 1).

In domain VI (see Table 2), the limitations resulted mainly from the following factors: $60 \%(n=180)$ complained of rapid fatigue during daily work, $44.7 \%(n=134)$ were affected by overweight, $42.0 \%(n=126)$ of subjects reported no regular physical activity, and $86.0 \%$ $(n=258)$ of subjects were not aware of the currently required vaccinations. This factor was the main contributor to the unmet needs in domain VI and, consequently, this area was found to require the most support.

In the last domain, VII, 66.3\% ( $n=199)$ of the studied group reported memory issues (forgetting), 63.0\% $(n=189)$ experienced loneliness, $65.3 \%(n=196)$ presented problems sleeping, and $75 \%(n=225)$ were in pain. Additionally, $1 / 3$ of the group experienced depression and a lack of interest. In the remaining domains the problems were caused by such elements as in domain I; most difficulties resulted from hearing impairment and the 
inability to use the phone $(14.3 \%)$; in domain II, $27.3 \%(n=82)$ of participants complained of difficulties with performing housework, whereas $53.7 \%(n=161)$ reported problems with urine incontinence and $43.7 \%(n=131)$ with bowel movements.

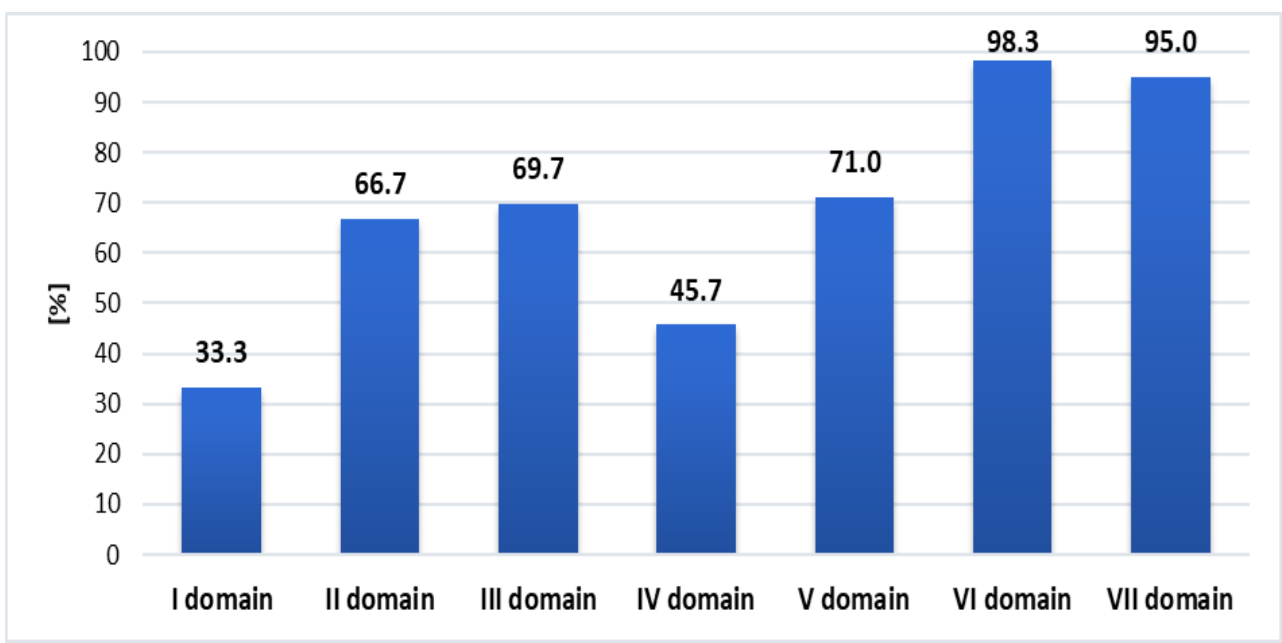

Figure 1. The percentage of needs (lack of independence) in particular domains. I: seeing, hearing, and communicating (4 items); II: looking after yourself (13 items); III: getting around (8 items); IV: your safety (5 items); V: your accommodation and finance ( 3 items); VI: staying healthy (7 items); and VII: your mental health and well-being (9 items).

Table 2. The most frequent limitations in EASYCare Standard 2010 questionnaire.

\begin{tabular}{|c|c|c|c|c|}
\hline \multirow{2}{*}{ EASYCare Domain } & \multirow{2}{*}{$\begin{array}{l}\text { Study Group } \\
\text { N (\%) }\end{array}$} & \multicolumn{2}{|c|}{ Number of Subjects Reporting Needs in the Domain } & \multirow{2}{*}{$p$ Value } \\
\hline & & 60-69 Years of Age N (\%) & Over 70 Years of Age $N(\%)$ & \\
\hline $\begin{array}{l}\text { I: Seeing, hearing, and } \\
\text { communicating ( } 4 \text { items) }\end{array}$ & $100(33.3 \%)$ & $38(23.2 \%)$ & $62(45.6 \%)$ & $<0.001$ * \\
\hline II: Looking after yourself (13 items) & $200(66.7 \%)$ & $91(55.5 \%)$ & $109(80.1 \%)$ & $<0.001$ * \\
\hline III: Getting around (8 items) & $209(69.7 \%)$ & $98(59.8 \%)$ & $111(81.6 \%)$ & $<0.001$ * \\
\hline IV: Your safety (5 items) & $137(45.7 \%)$ & $65(39.6 \%)$ & $72(52.9 \%)$ & $0.027 *$ \\
\hline $\begin{array}{l}\text { V: Your accommodation and finance } \\
\text { (3 items) }\end{array}$ & $213(71.0 \%)$ & $116(70.7 \%)$ & $97(71.3 \%)$ & $1.000 *$ \\
\hline VI: Staying healthy (7 items) & $295(98.3 \%)$ & $160(97.6 \%)$ & $135(99.3 \%)$ & 0.049 * \\
\hline $\begin{array}{l}\text { VII: Your mental health and } \\
\text { well-being (9 items) }\end{array}$ & $285(95.0 \%)$ & $157(95.7 \%)$ & $128(94.1 \%)$ & $0.600 *$ \\
\hline \multicolumn{5}{|l|}{ Summary scales } \\
\hline Independence score & $13.3 \pm 18.1$ & $8.8 \pm 14.5$ & $18.6 \pm 20.6$ & $0.000 * *$ \\
\hline Risk of breakdown in care & $4.4 \pm 2.4$ & $4.1 \pm 2.4$ & $4.9 \pm 2.4$ & $<0.001^{* *}$ \\
\hline Risk of falls & $1.8 \pm 1.6$ & $1.4 \pm 1.5$ & $2.2 \pm 1.7$ & $<0.001^{* *}$ \\
\hline
\end{tabular}

${ }^{*}$ chi $^{2}$ test; ${ }^{* *}$ Mann-Whitney test.

In domain III half $(50.0 \%, n=150)$ of the subjects complained of problems with feet, whereas $43.7 \%(n=131)$ experienced falls in the last 12 months, and $28.7 \%(n=86)$ of participants were unable to go shopping by themselves.

In terms of personal safety (domain IV), 37\% $(n=111)$ of subjects indicated that they did not feel safe outside their homes. In domain $\mathrm{V}$, your accommodation and finance, $67.7 \%$ $(n=203)$ of participants wished to obtain information regarding financial assistance. 
The resulting limitations in individual domains have been reflected in the three scales summarizing the EASYCare Standard 2010 questionnaire. The average scores in the three summary scales were: independence score-13.3 \pm 18.1 , risk of breakdown in care$4.4 \pm 2.4$, risk of falls $-1.8 \pm 1.6$. The results confirm the high functionality of the group.

Taking into consideration the demographic variables, significant differences $(p<0.05)$ were found between independence in the three summary scales and age, marital status, education, and requiring a carer. No difference $(p>0.05)$ was observed with regard to place and form of residence. The analysis of age according to the groups demonstrated that with age, the efficiency of the elderly in performing independent care activities decreases, which was reflected in the results of the three scales summarizing the questionnaire EASYCare Standard 2010.

\subsection{Rosenberg Self-Esteem Scale vs. Questionnaire EASYCare Standard 2010}

The Spearman rank correlation coefficient $R_{S}$ demonstrated a correlation between selfesteem (RSES) and the functional level of the elderly in all domains and three EASYCare Standard 2010 summary scales. The following results were obtained: with an increased risk of dependence (independence score $\mathrm{rs}=-0.295, p<0.001$ ), increased risk of breakdown in care rs $=-0.453, p<0.001$ ), increased risk of falls (risk of falls rs $=-0.301, p<0.001$ ), and lower self-assessment scores were observed.

\subsection{Rosenberg Self-Esteem Scale vs. Questionnaire EASYCare Standard 2010 and Demographic and Social Variables}

Demographic factors were selected for the logistic regression univariate model (see Table 3), as well as the domains and summary scales of the EASYCare Standard 2010 questionnaire, which scored $p<0.05$ in the earlier analysis using RSES. All factors were found to be significant, except for the place of residence. It should be emphasized that in domains VI and VII the majority of subjects reported unmet needs, which resulted in statistically insignificant results in the analysis $(p>0.05)$.

The conducted multivariate analysis (see Table 3 ) demonstrated that a low self-esteem was at least three times more common among individuals with an education below the secondary level and more than twice as often in subjects with a poor financial condition. Furthermore, participants who reported no needs in domain I (seeing, hearing, and communicating skills) were three times less likely to experience low self-esteem.

Table 3. Logistic regression-univariate model and multivariate model for self-esteem $(Y=1-$ low; $\mathrm{Y}=0$ - high self-esteem).

\begin{tabular}{|c|c|c|c|c|c|c|c|c|}
\hline \multirow{2}{*}{$\begin{array}{l}\text { Logistic Regression } \\
\text { Analysed Domain } \\
\text { (Reference Level) }\end{array}$} & \multicolumn{4}{|c|}{ Univariate Model } & \multicolumn{4}{|c|}{ Multivariate Model } \\
\hline & OR & $95 \% \mathrm{CI}$ & & $p$-Value & OR & $95 \% \mathrm{Cl}$ & & $p$-Value \\
\hline $\begin{array}{l}\text { Age } \\
\text { (60-69 years of age) }\end{array}$ & 0.73 & 0.43 & 1.24 & 0.242 & & & & \\
\hline $\begin{array}{l}\text { Gender } \\
\text { (women) }\end{array}$ & 1.21 & 0.70 & 2.09 & 0.481 & & & & \\
\hline $\begin{array}{l}\text { Place of residence } \\
\text { (city) }\end{array}$ & 0.65 & 0.34 & 1.21 & 0.172 & & & & \\
\hline $\begin{array}{l}\text { Marital status } \\
\text { (single) }\end{array}$ & 1.21 & 0.70 & 2.09 & 0.481 & & & & \\
\hline $\begin{array}{l}\text { Form of residence } \\
\text { (alone) }\end{array}$ & 0.53 & 0.23 & 1.24 & 0.136 & & & & \\
\hline $\begin{array}{l}\text { Education } \\
\text { (below the secondary level) }\end{array}$ & 4.25 & 2.36 & 7.67 & $<0.001$ & 3.54 & 1.91 & 6.56 & $<0.001$ \\
\hline
\end{tabular}


Table 3. Cont.

\begin{tabular}{|c|c|c|c|c|c|c|c|c|}
\hline \multirow{3}{*}{$\begin{array}{l}\text { Logistic Regression } \\
\begin{array}{l}\text { Analysed Domain } \\
\text { (Reference Level) }\end{array} \\
\begin{array}{l}\text { Financial condition } \\
\text { (poor financial condition) }\end{array}\end{array}$} & \multicolumn{4}{|c|}{ Univariate Model } & \multicolumn{4}{|c|}{ Multivariate Model } \\
\hline & \multirow{2}{*}{$\begin{array}{l}\text { OR } \\
2.98\end{array}$} & \multicolumn{2}{|c|}{$95 \% \mathrm{CI}$} & \multirow{2}{*}{$\begin{array}{l}p \text {-Value } \\
<0.001\end{array}$} & \multirow{2}{*}{$\begin{array}{l}\text { OR } \\
2.49\end{array}$} & \multicolumn{2}{|c|}{$95 \%$ CI } & \multirow{2}{*}{$\begin{array}{l}p \text {-Value } \\
<0.010\end{array}$} \\
\hline & & 1.72 & 5.17 & & & 1.28 & 4.31 & \\
\hline $\begin{array}{l}\text { Requiring a carer } \\
\text { (yes) }\end{array}$ & 3.66 & 2.05 & 6.55 & $<0.001$ & & & & \\
\hline $\begin{array}{l}\text { Place of residence } \\
\text { (living in the city) }\end{array}$ & 0.65 & 0.34 & 1.21 & 0.172 & & & & \\
\hline I (Lack of need) & 0.27 & 0.15 & 0.46 & $<0.001$ & 0.29 & 0.17 & 0.54 & $<0.001$ \\
\hline II (Lack of need) & 0.52 & 0.28 & 0.96 & 0.034 & & & & \\
\hline III (Lack of need) & 0.50 & 0.26 & 0.95 & 0.032 & & & & \\
\hline IV (Lack of need) & 0.24 & 0.17 & 0.44 & $<0.001$ & & & & \\
\hline V (Lack of need) & 0.25 & 0.11 & 0.54 & $<0.001$ & & & & \\
\hline \multicolumn{9}{|l|}{ VI (Lack of need) } \\
\hline VII (Lack of need) & 0.22 & 0.29 & 1.73 & 0.077 & & & & \\
\hline $\begin{array}{l}\text { Independence score } \\
\text { (Independence) }\end{array}$ & 0.31 & 0.18 & 0.54 & $<0.001$ & & & & \\
\hline $\begin{array}{l}\text { Risk of breakdown in care } \\
\text { (Risk) }\end{array}$ & 3.85 & 2.17 & 7.14 & $<0.001$ & & & & \\
\hline $\begin{array}{l}\text { Risk of falls } \\
\text { (point } 1-2 \text { ) }\end{array}$ & 0.20 & 0.12 & 0.36 & $<0.001$ & & & & \\
\hline
\end{tabular}

OR-odds ratio, $95 \%$ CI-confidence interval.

\section{Discussion}

The majority of study participants were aged 60-69 years. Most of them lived with their spouse or children in urban areas, their financial condition was good, and they had at least been achieved secondary education. Good cognitive functioning was confirmed with the AMTS scale in all subjects. Additionally, most of the participants presented high self-esteem (29.9 points). However, the RSES score only slightly exceeded the threshold we adopted. A high self-esteem in the elderly has also been reported by other authors, although they simultaneously emphasise that it decreases with age $[1,17,24]$. The changing roles may account for this phenomenon, particularly bearing in mind elements such as children moving out, retirement, poorer financial situation, and deteriorating health and also a reduced participation in family life, or insufficient social support [3,6,34].

Although the participants demonstrated a high level of independence in the EASYCare Standard questionnaire 2010 and, therefore, a low risk of disability (independence score), institutional care (risk of breakdown in care scale) or falls (risk of falls scale), they also reported a relatively high number of needs requiring support. Moreover, the elderly expected most assistance in area VI (staying healthy) and VII (your mental health and well-being) included in the EASYCare Standards 2010 questionnaire. In terms of the needs, the elderly most frequently indicated the need for pain relief ( $2 / 3$ of the group), improving their knowledge about current vaccinations, and the possibilities of financial support. The importance of vaccinations in the elderly was already emphasised in 2010 by the experts of the European Union Geriatric Medicine Society and the International Association of Gerontology and Geriatrics European Region. The most commonly recommended vaccinations include: influenza, tetanus, diphtheria, pertussis, pneumococcus, and shingles [35]. Furthermore, the recently developing pandemic has prompted an additional recommendation for vaccination against COVID-19 (coronavirus disease 2019), particularly in the elderly. 
Other issues reported by more than $50 \%$ of the group were: experiencing shortness of breath while doing housework, sleep disorders, incontinence, foot problems, and overweight. All of the aforementioned disorders are commonly identified as factors limiting the independence of the elderly and deteriorating their self-esteem [26,27]. In area VII, the subjects particularly highlighted forgetfulness, as well as feelings of despondency and loneliness. In fact, the feeling of loneliness and isolation frequently accompanies the elderly and adversely affects their self-esteem, reducing their quality of life [12,24,36]. In addition, loneliness can also lead to serious health issues [18]; therefore, it is crucial for the elderly to maintain interpersonal relationships, particularly with family $[3,12,15,16,23]$. The level of independent functioning largely depends on mood. In the study group, lowered mood was present in 1/3 of the group and was accompanied by problems, such as forgetfulness, feelings of loneliness, sleep disorders, and chronic pain. It is vital to bear in mind that lowered mood, particularly depression, is a factor significantly associated with low self-esteem $[12,13,15,16]$.

In the conducted study, the independent correlates of low self-esteem were education below the secondary level, having a carer, a poorer financial condition, and unmet needs in Area I: seeing, hearing, and communicating and IV: your safety. According to Tavares et al. [24], sensory functions affect the quality of social interactions. They allow for interaction with their environment and also influence a person's independence. Therefore, a deterioration of vision, hearing, or speech fluency disorders all promote low self-esteem.

Rosenberg and Pearlin remarked as early as 1978 that poorer education is associated with poorer self-esteem [10]. It is believed that higher education is one of the factors which allow us to manage the challenges posed by the aging process more effectively [12]. Additionally, it also promotes a better financial condition, which plays a significant role in self-perception $[3,8,20]$.

The logistic regression-univariate model additionally revealed a significant association between low self-esteem and the need for a carer. A total of $24 \%$ of the study participants received care from others. This group included individuals who were less functional and required support in daily activities. According to a study conducted in the UK, approximately $20 \%$ of men and $30 \%$ of women over 65 years of age require assistance with at least one activity of daily living (ADL) [29]. The most common sources of disability include ailments resulting from chronic diseases and comorbidities. In turn, functional limitations and the experienced ailments negatively affect mood and self-esteem [1,19]. In contrast, coping with the disease is also influenced by self-compassion, which is a feeling facilitating the acceptance of pain and other disorders or imperfections allowing one to take care of oneself. It is particularly important in the elderly, as disorders increase and the functional capacity decreases with age. High self-esteem positively affects self-compassion [13]. The ability to function independently is frequently indicated as a major determinant of a high quality of life and self-esteem [14,25-27]. In contrast, poor independence decreases self-esteem $[2,20,21]$.

The results obtained in the conducted study demonstrate that age represents an important determinant of caregiving needs, and that despite good functional ability, the elderly require support on the part of others. Therefore, when planning care for the elderly, both nationally and individually, particular attention should be paid to the appropriate choice of support to extend independent functioning [37]. It is also essential to increase the activity of the elderly in all areas of life [12,18], as well as to take into account the individual differences in the functioning of elderly persons, and not to focus only on the disabled. The abovementioned measures will contribute not only to increasing the independence of the elderly, but also to their increased self-esteem and a better quality of life $[8,10]$.

Measures aimed at increasing self-esteem in the elderly include:

1. Developing social connections. The elderly surrounded by family and friends present higher self-esteem. 2. Eliminating negative stereotypes. Positive attitudes towards the elderly motivate them to take on new challenges in life. 3. Exploring the views and opinions of the elderly. This offers insight into their perception of current events and provides 
information regarding changes in their environment. 4. Using the experience and knowledge of the elderly. 5. Adapting the accommodation to the degree of disability and ensuring safe mobility. Physical activity helps prevent falls and maintains independent functioning.

Good self-esteem facilitates understanding and acceptance of the ageing process and thus should be taken into account when organising care for the elderly [3]. Moreover, providing appropriate support is possible when monitoring the elderly's functional status and self-esteem. However, in order to do so, appropriate programmes and legislation need to be implemented.

\section{Study Limitations}

The study included fit individuals over 60 years of age. In the future, the study group should be extended to include subjects at a significantly lower functional level and in greater need of support. This would possibly demonstrate that some care needs increase with age, whereas other needs increase with disability. First of all, increasing the group size would allow for the identification of subgroups and a more accurate analysis of changes in self-esteem, e.g., separately for younger and older men, or women, as well as for individuals with a higher or lower functionality level. Secondly, the study involved a subjective assessment. Although we used the reliable RSES and EASYCare Standard 2010 tools, a verification of the actual functioning at home would certainly have produced more objective results. Finally, in the statistical analysis, in terms of the predictors affecting self-esteem, we did not include the number of diseases or persistent complaints.

\section{Conclusions}

The results confirm that even successfully ageing individuals require regular assessment of their functional status and individually adapted support in order to maintain independence. Therefore, scales to determine the need for support, e.g., the EASYCare Standard 2010, should be introduced and obligatorily used by community nurses and social services.

Multivariate logistic regression found a relationship between low self-esteem and a poor financial condition, poor education, and sight, hearing, and communication problems. Furthermore, the predictors of low self-esteem revealed the specificity of activities to be included in programmes aimed at the elderly: 1. regular check-ups of sight and hearing and fitting of suitable prostheses; 2 . preparing and providing the elderly with information on the possibilities of financial and material support; and 3. providing access to and encouraging participation in various forms of lifelong learning.

Nevertheless, in order to achieve the objectives of such a programme, it is essential to develop and implement a comprehensive strategy aiming to improve the quality of life of the elderly and to increase their self-esteem.

Author Contributions: Conceptualization, D.T. and K.W.-T.; methodology, D.R.-Ł., S.K. and D.T.; formal analysis: S.T. and S.K.; writing-original draft, D.T.; writing-review and editing, D.T., K.W.-T. and S.K.; supervision, D.T., K.W.-T. and D.R.-- . All authors have read and agreed to the published version of the manuscript.

Funding: The authors received no financial support for the research, authorship, and/or publication of this article.

Institutional Review Board Statement: The study was conducted in accordance with the Declaration of Helsinki, and approved by the Institutional Review Board of Bioethics Committee, Poznan University of Medical Sciences (protocol code 950/15).

Informed Consent Statement: Informed consent was obtained from all subjects involved in the study.

Data Availability Statement: The datasets used during the current study are available from the corresponding author on reasonable request.

Conflicts of Interest: The authors declared no potential conflict of interest with respect to the research, authorship, and/or publication of this article. 


\section{References}

1. Orth, U.; Erol, R.Y.; Luciano, E.C. Development of Self-Esteem from Age 4 to 94 Years: A Meta-Analysis of Longitudinal Studies. Psychol. Bull. 2018, 144, 1045-1080. [CrossRef] [PubMed]

2. Moral-García, J.E.; García, D.O.; García, S.L.; Jiménez, M.A.; Dios, R.M. Influence of physical activity on self-esteem and risk of dependence in active and sedentary elderly people. An. Psicol. Ann. Psychol. 2018, 34, 162-166. [CrossRef]

3. Meira, S.S.; Vilela, A.B.A.; Casotti, C.A.; Silva, D.M.d. Self esteem and factors associated with social conditions in the elderly. Rev. Pesqui. Cuid. Fundam. Online. 2017, 9, 738-744. [CrossRef]

4. von Soest, T.; Wichstrøm, L.; Lundin Kvalem, I. The development of global and domain-specific self-esteem from age 13 to 31. J. Pers. Soc. Psychol. 2016, 110, 592-608. [CrossRef] [PubMed]

5. Rosi, A.; Cavallini, E.; Gamboz, N.; Vecchi, T.; Tijmen Van Vugt, F.; Russo, R. The Impact of Failures and Successes on Affect and Self-Esteem in Young and Older Adults. Front. Psychol. 2019, 10, 1795. [CrossRef]

6. Ogihara, Y. A Decline in Self-Esteem in Adults over 50 Is Not Found in Japan: Age Differences in Self-Esteem from Young Adulthood to Old Age. BMC Res. Notes 2019, 12, 274. [CrossRef]

7. Karki, K.; Sapkota, A.; Jajko, S.; Raj Singh, D. Socio-demographic variables related to self-esteem, psychological stress and health-related quality of life among older adults: A cross-sectional study in Kavrepalanchowk district of Nepal. SAGE Open Med. 2021, 9, 20503121211056437. [CrossRef]

8. Ingrand, I.; Paccalin, M.; Liuu, E.; Gil, R.; Ingrand, P. Positive Perception of Aging Is a Key Predictor of Quality-of-Life in Aging People. PLoS ONE 2018, 13, e0204044. [CrossRef]

9. Chen, J.; Zheng, K.; Xia, W.; Wang, Q.; Liao, Z.; Zheng, Y. Does Inside Equal Outside? Relations Between Older Adults' Implicit and Explicit Aging Attitudes and Self-Esteem. Front. Psychol. 2018, 9, 2313. [CrossRef]

10. Franak, J.; Alireza, K.; Malek, M. Self-Esteem Among the Elderly Visiting the Healthcare Centers in Kermanshah-Iran (2012). Glob. J. Health Sci. 2015, 7, 352-358. [CrossRef]

11. Alaphilippe, D. Self-esteem in the elderly. Psychol. Neuropsychiatr. Vieil. 2008, 6, 167-176. [CrossRef] [PubMed]

12. Šare, S.; Ljubičić, M.; Gusar, I.; Čanović, S.; Konjevoda, S. Self-Esteem, Anxiety, and Depression in Older People in Nursing Homes. Healthcare 2021, 9, 1035. [CrossRef] [PubMed]

13. Hwang, S.; Kim, G.; Yang, J.-W.; Yang, E. The Moderating Effects of Age on the Relationships of Self-Compassion, Self-Esteem, and Mental Health. Jpn. Psychol. Res. 2016, 58, 194-205. [CrossRef]

14. de Lima, T.J.S.; de Souza, L.E.C. Rosenberg Self-Esteem Scale: Method Effect and Gender Invariance. Psico-USF 2019, 24, 517-528. [CrossRef]

15. Ali, S.A. Low Self-Esteem Leads to Depression Among Elderly: Case Study of Nursing Home. J. Univers. Surg. $2016,4,4$.

16. Lee, H.J.; Lee, D.K.; Song, W. Relationships between Social Capital, Social Capital Satisfaction, Self-Esteem, and Depression among Elderly Urban Residents: Analysis of Secondary Survey Data. Int. J. Environ. Res. Public Health 2019, 16, 1445. [CrossRef]

17. Bleidorn, W.; Arslan, R.C.; Denissen, J.J.A.; Rentfrow, P.J.; Gebauer, J.E.; Potter, J.; Gosling, S.D. Age and Gender Differences in Self-Esteem-A Cross-Cultural Window. J. Pers. Soc. Psychol. 2016, 111, 396-410. [CrossRef]

18. Szcześniak, M.; Bielecka, G.; Madej, D.; Pieńkowska, E.; Rodzeń, W. The Role of Self-Esteem in the Relationship between Loneliness and Life Satisfaction in Late Adulthood: Evidence from Poland. Psychol. Res. Behav. Manag. 2020, 13, 1201-1212. [CrossRef]

19. Kristensen, K.; König, H.-H.; Hajek, A. The Association of Multimorbidity, Loneliness, Social Exclusion and Network Size: Findings from the Population-Based German Ageing Survey. BMC Public Health 2019, 19, 1383. [CrossRef]

20. de Oliveira, D.V.; do Nascimento, M.A.; Fernandes, A.; Franco, M.F.; do Nascimento Júnior, J.R.A. Self-esteem among older adults treated at basic health units and associated factors. Geriatr. Gerontol. Aging 2019, 13, 133-140. [CrossRef]

21. Sales, M.; Levinger, P.; Polman, R. Relationships between Self Perceptions and Physical Activity Behaviour, Fear of Falling, and Physical Function among Older Adults. Eur. Rev. Aging Phys. Act. 2017, 14, 17. [CrossRef] [PubMed]

22. Lin, Y.; Xiao, H.; Lan, X.; Wen, S.; Bao, S. Living Arrangements and Life Satisfaction: Mediation by Social Support and Meaning in Life. BMC Geriatr. 2020, 20, 136. [CrossRef] [PubMed]

23. Ilyas, Z.; Shahed, S.; Hussain, S. An Impact of Perceived Social Support on Old Age Well-Being Mediated by Spirituality, Self-Esteem and Ego Integrity. J. Relig. Health 2020, 59, 2715-2732. [CrossRef] [PubMed]

24. Tavares, D.M.D.S.; Matias, T.G.C.; Ferreira, P.C.D.S.; Pegorari, M.S.; Nascimento, J.S.; Paiva, M.M. de Quality of life and self-esteem among the elderly in the community. Cienc. Saude Coletiva 2016, 21, 3557-3564. [CrossRef]

25. Ulfiana, E.; Saelindra, M.; Suyatmana, S.H. Level of Independence towards Self-Esteem in The Elderly; Atlantis Press: Boynton Beach, FL, USA, 2017; pp. 140-142. [CrossRef]

26. Şavkin, R.; Bayrak, G.; Büker, N. Balance, Falls, Fear of Falling, and Foot Function in Elderly People in Community-Dwelling Older Adults. Acıbadem Üniversitesi Sağlık Bilim. Derg. 2021, 12, 279-283. [CrossRef]

27. Klompstra, L.; Ekdahl, A.W.; Krevers, B.; Milberg, A.; Eckerblad, J. Factors Related to Health-Related Quality of Life in Older People with Multimorbidity and High Health Care Consumption over a Two-Year Period. BMC Geriatr. 2019, 19, 187. [CrossRef]

28. Shrivastava, S.R.B.L.; Shrivastava, P.S.; Ramasamy, J. Health-care of Elderly: Determinants, Needs and Services. Int. J. Prev. Med. 2013, 4, 1224-1225. 
29. Abdi, S.; Spann, A.; Borilović, H.; de Witte, L.; Hawley, M. Understanding the care and support needs of older people: A scoping review and categorisation using the WHO international classification of functioning, disability and health framework (ICF). BMC Geriatr. 2019, 22, 195. [CrossRef]

30. Brandão, M.P.; Martins, L.; Philp, I.; Cardoso, M.F. Reliability and Validity of the EASYCare-2010 Standard to Assess Elderly People in Portuguese Primary Health Care. Aten. Primaria 2017, 49, 576-585. [CrossRef]

31. Pınar, R.; Ergün, A.; Erol, S.; Kurtuluş, Z.; Gür, K.; Sert, H.; Philp, I. The Adaptation of the Easy-Care Standard Assessment Instrument into Turkish and Evaluation of Psychometric Properties among Turkish Older People. Nobel Med. 2015, 11, 85-92.

32. Hodkinson, H.M. Evaluation of a Mental Test Score for Assessment of Mental Impairment in the Elderly. Age Ageing 1972, 1 , 233-238. [CrossRef] [PubMed]

33. Tobis, S.; Jaracz, K.; Talarska, D.; Kropińska, S.; Zasadzka, E.; Pawlaczyk, M.; Wieczorowska-Tobis, K.; Philp, I.; Suwalska, A. Validity of the EASYCare Standard 2010 Assessment Instrument for Self-Assessment of Health, Independence, and Well-Being of Older People Living at Home in Poland. Eur. J. Ageing 2018, 15, 101-108. [CrossRef] [PubMed]

34. Nanthamongkolchai, S.; Makapat, A.; Charupoonphol, P.; Munsawaengsub, C. Self-esteem of the elderly in rural areas of Nakhon Sawan Province. J. Med. Assoc. Thai. 2007, 90, 155-159. [PubMed]

35. Weinberger, B. Vaccines for the Elderly: Current Use and Future Challenges. Immun. Ageing 2018, 15, 3. [CrossRef] [PubMed]

36. Zhao, L.; Zhang, X.; Ran, G. Positive Coping Style as a Mediator between Older Adults' Self-Esteem and Loneliness. Soc. Behav. Personal. Int. J. 2017, 45, 1619-1628. [CrossRef]

37. Ahn, M.; Kwon, H.J.; Kang, J. Supporting Aging-in-Place Well: Findings From a Cluster Analysis of the Reasons for Aging-in-Place and Perceptions of Well-Being. J. Appl. Gerontol. 2020, 39, 3-15. [CrossRef] 